\title{
The Optimal Prudential Deterrence of Price Fixing Agreements
}

\author{
Michele Polo \\ Bocconi University \\ and \\ IGIER, Milan * \\ First version: December 1996 \\ this version: September 1997
}

\begin{abstract}
We analyse the optimal antitrust enforcement against collusion under asymmetric information with a continuum of types. We focus on prudential deterrence, by imposing that expected fines cannot induce losses even off the equilibrium path. Due to incentive compatibility, efficient cartels enjoy positive rents even when prosecution is costless, created through reduced fines and price cost margins. In equilibrium this distortion is lower for more efficient types, while full collusion can be tolerated for high cost cartels. Moreover, regulation with positive transfers is better than antitrust enforcement, which however allows to implement more efficient outcomes than price caps.
\end{abstract}

Keywords: Optimal enforcement, Antitrust, Regulation JEL Classification: D21, L4

\footnotetext{
*Mailing Address: Prof. Michele Polo, Universita' Bocconi, Via Sarfatti 25, 20136 Milan, Italy, tel. ++39.2.5836.3307, fax ++39.2.5836.3302, e-mail michele.polo@unibocconi.it. I would like to thank Sandro Brusco, Gianni De Fraja, Michele Grillo, Giovanni Maggi, Massimo Motta, Fausto Panunzi, Carlo Scarpa, Said Souam, Jean Tirolee and especially Patrick Rey for useful discussions. The author thanks IDEI (Toulouse) for hospitality and Fondazione Mattei and Ricerca di Base, Bocconi University for financial support. All remaining errors are mine.
} 


\section{Introduction}

Competition policy is today one of the building blocks of supply side public intervention in the economy in all the industrialized countries. It tends to gain a major role, and eventually to replace the more traditional and discretionary tools of industrial policy based of transfers and subsidies to specific industries or firms. Moreover, it is often the natural candidate to promote public intervention in industries that were previously monopolized and regulated.

It seems therefore important to understand how the normative analysis of optimal antitrust enforcement can be developed. The main reference is the literature on the optimal enforcement of law which originated from the seminal paper by Becker (1968). Recent developments in this field formalize optimal enforcement as a mechanism design problem ${ }^{1}$ in which the public authority uses fines and the probability of intervention to implement, through the expected penalty schedule, second best optimal actions given the incentive constraints that arise from asymmetric information.

This analytical framework can be applied quite naturally to the problem of optimal enforcement of competition policy. Although the analysis is normative in nature, the description of the set of instruments and constraints that identify antitrust is usually positive, i.e. it draws from the main features of competition policy as observed in practice. For instance, competition policy is associated to the fines that can be imposed if firms are proved to be guilty, with no power to prescribe explicitly the price or any other specific (legal) conduct. In other words, the key questions addressed are how to use fines, the probability of intervention etc. in an optimal way, while it is left aside, for example, why the authority should be restricted to use only negative transfers to firms and not positive ones.

If the antitrust authority had full information on firms' types, no cost of prosecution and unbounded fines, the first best would be attainable: a fine sufficiently high to prevent any type from collusion would induce firms to prefer legal (non cooperative) behaviour. Antitrust enforcement becomes interesting because in real situations the authority has informational constraints, limited resources and bounded penalties. The optimal allocations implemented depend, in turn, on the particular features of these three sets of constraints.

The more relevant reference in the field is so far the paper by Besanko

\footnotetext{
${ }^{1}$ See Mookherjee and Png (1994).
} 
and Spulberg (1989), where the authors analyse the optimal design of antitrust intervention under asymmetric information when there are two types of cartels (costs). The enforcer commits to a set of instruments, i.e. fines and probability of intervention, which make the expected penalties contingent on some observed signal, as for instance the market price. They find that in a separating equilibrium the efficient cartel colludes and is not prosecuted, while the high cost cartel is induced to competitive (Bertrand) behaviour and is monitored with positive probability. The Besanko and Spulberg setting is generalized in Penard and Souam (1996) to the case of a continuum of types. The optimal allocations implementable maintain the same qualitative features of the original paper: the efficient types collude while the less efficient ones are induced to choose non cooperative behaviour through sufficiently high fines that would imply negative payoff if collusion occurred.

Considering the three sets of constraints which usually characterize the enforcement problem, in the Besanko and Spulberg setting the use of sufficiently high fines enables the enforcer to circumvent the asymmetric information problem, provided that the costs of enforcement is negligible: since ex-post monitoring allows to ascertain if illegal behaviour occurred, high fines would induce firms not to collude at all; if prosecution were not costly, any type would be monitored in equilibrium and would prefer to behave non-cooperatively. In turn, the features of optimal enforcement depend on the constraint of costly enforcement.

In this paper we try to explore the antitrust enforcement problem considering an additional feature that often characterizes competition policy: since firms can implement price cost margins through (legal but unobserved) non cooperative behaviour as well as through collusion, and since the monitoring technology hardly excludes that an innocent firm might be condemned, there is always the possibility that a firm has to pay an unexpected fine. If we want to exclude that competition policy forces the exit of firms, we have to set some restrictions on the use of fines. Relying on this general motivation, in our model we assume that the expected penalties cannot be higher than gross profits, i.e. that the participation constraint holds, even off the equilibrium path. We call this restriction prudential deterrence, as opposed to the approach in the Besanko and Spulberg setting.

We find that the price schedule implementable is increasing, while the net profits are decreasing in cartel's costs. Consequently, efficient cartels have positive informational rents according to the incentive compatible mechanisms. Moreover, the expected penalty schedule must be increasing if a price lower than the monopoly level is implemented. Since the most favourable 
penalty can be at most zero, the rents for efficient types must be created through price cost margins. However, with prudential enforcement we cannot prevent inefficient types from partially collude, as in the Besanko and Spulberg setting. The optimal price schedule, in fact, entails prices higher than costs for all the types, with larger allocative distortions for less efficient types, which can eventually implement full collusion and pay (in expected terms) the associated maximum penalty.

Once characterized the optimal allocations implementable through prudential enforcement, it is interesting to compare them with those that would occur if the industry were regulated. Antitrust and regulation are in fact often alternative candidates to promote public intervention in very concentrated markets. For instance, the privatization of public utilities is today considered firstly as a problem of industry reform ${ }^{2}$, and the distinction of the vertical segments which are natural monopoly from those where competition can be promoted has led in many cases to create a much more articulated industry structure. Antitrust is then in many submarkets an alternative to regulation, and a comparison of the two schemes of intervention seems necessary.

The modern theory of regulation ${ }^{3}$ analyses the choice of optimal regulatory schemes as a mechanism design problem under asymmetric information. The analytical framework of the two approaches to public intervention is therefore the same, resulting in a quite natural comparison. We find that regulation with transfers dominates antitrust prudential enforcement, which however allows to implement more efficient allocations with respect to regulation without transfers (price caps).

The paper is organized as follows. Section 2 presents a model of antitrust intervention, while the optimal enforcement mechanism is discussed in section 3 . In section 4 we compare the allocations implementable with different regulatory regimes and those with antitrust enforcement. Some comments on further research in the field conclude the paper.

\section{A model of antitrust intervention}

Optimal deterrence of price fixing agreements will be the object of our analysis. Since in a cartel a group of firms act coordinately and promote an

\footnotetext{
${ }^{2}$ See for instance Amstrong et al (1995).

${ }^{3}$ See Baron (1989), Laffont and Tirole (1993), Laffont (1994).
} 
agreed and illegal strategy, those firms will be treated as a single entity, the cartel, which is the party prosecuted by the enforcer.

Firms offer identical products and industry demand is described by a continuous, finite, downward sloping and concave demand function $D(p)$, with $D^{\prime}<0, D^{\prime \prime}<0$ and $D(p)=0$ for $p \geq \bar{p}$. Costs are assumed to be perfectly correlated across firms, with $C_{i}=c \cdot q_{i}$. The marginal cost $c$ is drawn from a support $[\underline{c}, \bar{c}]$ according to a continuous distribution $g(c)$. The firms know their own marginal cost $c$.

We assume that non cooperative behaviour is Bertrand, with $p=c$ and zero profits for every firm; moreover we assume that the conditions for a tacit collusive agreement at the highest (monopoly) price are satisfied, for instance in terms of a sufficiently high discount factor. The action chosen by the cartel is assumed to be simply a price $p \in[0, \bar{p}]$. Hence, the gross profits of the cartel with costs $c$ are

$$
u_{c}(p)=(p-c) D(p)
$$

which, given the assumptions on $D(p)$, is differentiable, finite, concave and strictly decreasing in $c$. Let $p_{c}^{m}$ be the associated monopoly price which maximizes $u_{c}(p)$.

Consumers surplus in the industry is given by

$$
C S(p)=\int_{p}^{\bar{p}} D(s) d s
$$

The enforcer does not observe the realization of the marginal cost $c$ but knows the distribution $g(c)$ and the demand function $D(p)$, and (ex-post) observes the price $p$. More precisely, we assume that firms' costs are not observable either ex-ante or ex-post, through auditing. What the enforcer can eventually find when prosecuting a cartel is evidence of collusion, as for instance minutes of meetings, internal regulations that prescribe rules of reciprocal disclosure of information, etc. ${ }^{4}$.

The enforcement mechanism is described by a pair of functions $s(p) \epsilon$ $[0, \bar{s}]$ and $f(p) \in[0,1]$ which represent respectively the fine and the probability of being fined ${ }^{5}$. The expected penalty associated to a price $p$ is therefore

\footnotetext{
${ }^{4}$ We feel this assumption is quite close to actual antitrust enforcement, where proving collusion through an estimate of costs and monopoly price is usually not the case, while evidence of concerted practices is often the key argument for condemning.

${ }^{5}$ This latter can be related to different contingencies, as the probability of being discovered, the probability of being prosecuted and the probability of being found guilty. We
} 
$e s(p)=f(p) \cdot s(p) \in[0, \bar{s}]$. The costs of the enforcement policy are linear in the probability of intervention, i.e. $C_{e}=k \cdot f(p)$. We assume that the enforcer is able to commit ex ante to his enforcement policy.

The net profits of the cartel given the enforcement mechanism are

$$
\Pi_{c}(p)=u_{c}(p)-e s(p)
$$

All parties are assumed to be risk neutral. The enforcer is assumed to be benevolent and maximizes the sum of the surplus of the parties less the enforcement costs

$$
E W(p)=\int_{\underline{c}}^{\bar{c}}\left[C S(p)+e s(p)+\Pi_{c}(p)-k f(p)\right] g(c) d c
$$

We can now derive the optimal enforcement mechanism.

\section{The optimal enforcement of antitrust law}

Since we assumed that collusion is always viable while non cooperative behaviour yields zero profits, the only constraint to setting the monopoly price is given by the possibility of being fined. Hence, the cartel will maximize profits by setting a price that is optimal given the expected penalty. Let

$$
p_{c}=\arg \max _{p} \Pi_{c}(p)=u_{c}(p)-e s(p)
$$

$p_{c}$ defines the incentive compatible price schedule given the enforcement mechanism. The optimal mechanism will maximize the expected welfare (4) given the incentive compatibility constraint (5) and the participation constraint that no firm is forced to exit by competition policy, i.e.

$$
\Pi_{c}\left(p_{c}\right)=u_{c}\left(p_{c}\right)-e s\left(p_{c}\right) \geq 0 \quad \forall c \in[\underline{c}, \bar{c}]
$$

More precisely, the participation constraint will be relevant on and off the equilibrium path: a very severe penalty, in fact, may induce a firm to behave non cooperatively, getting zero profits in the Bertrand case assumed, rather than a negative payoff. We restrict the optimal policy not to induce such losses. The justification we have in mind, which is more general than the specific assumptions on the prosecution technology here adopted, is that in

do not distinguish so far among these different stages of the enforcement policy, leaving to future research this task. 
real cases it is always possible that an innocent firm is condemned. Hence, antitrust enforcement must be prudential, avoiding losses even off the equilibrium path.

Solving the problem as described above is rather cumbersome. Hence, we proceed according to Baron and Myerson (1982) by first identifying the implementable allocations that satisfy the two sets of constraints, and then by maximising the welfare function given the implementable allocations.

\subsection{Implementable allocations}

In this section we analyse the restrictions implied by the incentive compatibility and participation constraints of the original problem that can help to make it simpler. We restrict ourselves to implementing a piecewise continuous price schedule ${ }^{6}$ A first step is proved in the following lemma, using a revealed preferences argument.

Lemma 1 The incentive compatible schedule $p_{c}$ is non decreasing in $c$.

Proof: Let $c_{1}<c_{2}$ be two levels of the marginal cost. From the definition of $p_{c}$ it follows that

$$
\left(p_{c_{1}}-c_{1}\right) D\left(p_{c_{1}}\right)-e s\left(p_{c_{1}}\right) \geq\left(p_{c_{2}}-c_{1}\right) D\left(p_{c_{2}}\right)-e s\left(p_{c_{2}}\right)
$$

and

$$
\left(p_{c_{2}}-c_{2}\right) D\left(p_{c_{2}}\right)-e s\left(p_{c_{2}}\right) \geq\left(p_{c_{1}}-c_{2}\right) D\left(p_{c_{1}}\right)-e s\left(p_{c_{1}}\right)
$$

adding up and rearranging we obtain

$$
\left(c_{2}-c_{1}\right)\left(D\left(p_{c_{1}}\right)-D\left(p_{c_{2}}\right)\right) \geq 0
$$

which implies that $p_{c_{1}} \leq p_{c_{2}}$

Hence, an implementable price schedule cannot induce a lower price for a less efficient firm. The next step allows to characterize the net profits of a type $c$ firm according to the incentive compatible price schedule. Let

\footnotetext{
${ }^{6}$ In the optimal control problem that will be explicitly considered when solving for the optimal mechanism, this restriction amounts to the standard assumption that the control - the implementable price - is piecewise continuous.
} 


$$
\Pi_{c}\left(p_{c}\right)=u_{c}\left(p_{c}\right)-e s\left(p_{c}\right)
$$

be the net profits of a firm with cost $c$ selecting its incentive compatible price $p_{c}$.

Lemma $2 \Pi_{c}\left(p_{c}\right)$ is decreasing in $c$

Proof: $\quad$ Differentiating $\Pi_{c}\left(p_{c}\right)$ by $c$ we obtain

$$
\frac{d \Pi_{c}\left(p_{c}\right)}{d c}=-D\left(p_{c}\right)+\left(\frac{d u_{c}\left(p_{c}\right)}{d p}-\frac{d e s\left(p_{c}\right)}{d p}\right) \frac{d p_{c}}{d c}=-D\left(p_{c}\right)
$$

since the term in brackets is null due to the envelope theorem.

If the enforcer were informed about the cartel costs $c$, enforcement were costless and fines unbounded, the optimal solution would be to induce through a sufficiently high sanction each firm to set $p=c$, the first best solution, and firms of any type would obtain no profit. In an asymmetric information, costly prosecution and bounded fines environment, the more efficient firms gain positive profits, which are to be interpreted as rents from their informational advantage.

Using the results in Lemma 1 and 2, we can further characterize the incentive compatible expected penalty.

Lemma 3 If $p_{c}<p_{c}^{m}$, es $\left(p_{c}\right)$ is increasing at $p_{c}$.

Proof: $\quad$ Suppose $p_{c}<p_{c}^{m}$. Then $u_{c}\left(p_{c}\right)<u_{c}(p)$ for some $p>p_{c}$. From the definition of $p_{c}$ we know that $u_{c}(p)-e s(p) \leq u_{c}\left(p_{c}\right)-e s\left(p_{c}\right)$. Adding up the two inequalities and rearranging we obtain $e s\left(p_{c}\right)<e s(p)$ for some $p>p_{c}$.

We can summarize the features of the implementable allocations in the following way. The enforcer has to prevent the cartel from setting a high (monopoly) price through expected penalties. The incentive compatible price schedule on which the policy is built must be non decreasing in costs, allowing less efficient firms to recover higher costs through higher prices. In order to prevent a general upward movement of prices, however, expected penalties must be sufficiently increasing in price to prevent a more efficient 
cartel from setting its monopoly price by mimicking a higher cost one. The overall effect is a fall in net profits as costs increase. More efficient cartels enjoy a positive rent due to their informational advantage, while less efficient ones might break even. We can now move to the analysis of optimal allocations among the implementable ones.

\subsection{Optimal enforcement}

Let's consider first expected penalties for the most efficient type. We have shown that, if deterrence occurs for some prices (costs), it requires an expected penalty schedule increasing in the observed price. Define $p_{\underline{c}}<p_{\underline{c}}^{m}$ as the lowest price implementable. A corollary of Lemma 3 is that, since no deterrence is needed for prices lower than $p_{\underline{c}}$, being the gross profits $u_{c}(p)$ increasing in that region, the expected penalty can be flat for $p \leq p_{c}$. What is needed to ensure marginal deterrence is that the expected penalty is increasing to the right at $p_{\underline{c}}$.

Since expected penalties are costly in terms of welfare, it is optimal to set $e s(p)=0$ for $p \leq p_{\underline{c}}$, with eventually ${ }^{7}$ a kink at $p_{\underline{c}}$. Using this fact we can further characterize the expected penalities.

First of all, integrating ( 7 ) over $[c, \bar{c}]$ we obtain:

$$
\int_{c}^{\bar{c}} \frac{d \Pi_{c}\left(p_{c}\right)}{d c} d c=-\int_{c}^{\bar{c}} D\left(p_{c}\right) d c
$$

which, once solved, gives

$$
\Pi_{c}\left(p_{c}\right)=\Pi_{\bar{c}}\left(p_{\bar{c}}\right)+\int_{c}^{\bar{c}} D\left(p_{c}\right) d c
$$

Notice that, using the fact that $e s\left(p_{c}\right)=0$, the incentive compatible profits of the highest and lowest types are related by the following expression:

$$
\Pi_{\bar{c}}\left(p_{\bar{c}}\right)=u_{\underline{\underline{c}}}\left(p_{\underline{c}}\right)-\int_{\underline{c}}^{\bar{c}} D\left(p_{c}\right) d c
$$

Finally, using ( 8) and solving for the expected penalties of a type $c$ cartel we obtain

$$
e s\left(p_{c}\right)=u_{c}\left(p_{c}\right)-\Pi_{\bar{c}}\left(p_{\bar{c}}\right)-\int_{c}^{\bar{c}} D\left(p_{c}\right) d c
$$

\footnotetext{
${ }^{7}$ More precisely, a kink will occur if $p_{\underline{\subseteq}}<p_{\underline{c}}^{m}$.
} 
In order to ensure that $p_{\bar{c}}$ is the optimal price for a type $\bar{c}$ cartel, we must ensure that the expected penalties for prices higher than $p_{\bar{c}}$ are able to prevent the cartel from setting a higher (the monopoly) price. Since the highest gross profits are obtained at $p_{\bar{c}}^{m}$, in order to implement $p_{\bar{c}}$, expected penalites must be such that $\Pi_{\bar{c}}(p) \leq \Pi_{\bar{c}}\left(p_{\bar{c}}\right)$ for $p \in\left[p_{\bar{c}}, p_{\bar{c}^{m}}\right]$, which will hold as an equality at the lowest price schedule implementable. Using (9) and taking into account that the maximum expected penalty is $\bar{s}$, we obtain, after rearranging:

$$
\bar{s} \geq e s\left(p_{\bar{c}}^{\frac{m}{c}}\right)=u_{\bar{c}}\left(p_{\bar{c}}^{\frac{m}{c}}\right)-u_{\underline{c}}\left(p_{\underline{c}}\right)+\int_{\underline{c}}^{\bar{c}} D\left(p_{c}\right) d c
$$

which sets a constraint on the lowest price schedule implementable. It is evident from the expression above that if the enforcer wants to implement a lower price schedule, which decreases $u_{c}\left(p_{c}\right)$ and increases $D\left(p_{c}\right)$, a higher expected penalty schedule is required. Since a maximum penalty $\bar{s}$ is allowed, the enforcer is implicitly constrained on the set of implementable price schedules. Moreover, since expected penalties are increasing in observed prices and incentive compatible profits are decreasing in costs, we have to carefully check the participation constraint at the top.

The profits of the highest type when deviating to the monopoly price cannot be reduced below $u_{\bar{c}}\left(p \frac{m}{\bar{c}}\right)-\bar{s}$. Hence, the participation constraint at the top becomes

$$
\Pi_{\bar{c}}\left(p_{\bar{c}}\right) \geq \max \left\{0, u_{\bar{c}}(p \bar{m})-\bar{s}\right\}
$$

Summing up, if $\bar{s} \geq u_{\bar{c}}\left(p_{\bar{c}}\right)$ the participation constraint binds at the top with the highest type cartel breaking even; moreover, the informational rents of the most efficient cartel are minimized by implementing the lowest price schedule. If the maximum penalty is lower than the gross monopoly profits of the least efficient cartel, even this latter will have some rents and the implementable price schedules will be higher.

Let's now consider the selection of the implementable allocation which maximizes welfare given the participation and incentive compatibility constraints and the boundary conditions on the expected penalties. This can be framed as an optimal control problem in which the state variable is the net profit $\Pi_{c}\left(p_{c}\right)$ and the control variable is the price $p_{c} \in\left[c, p_{c}^{m}\right]$. We have seen that the set of participation constraints can be replaced by the condition (12), which means that we have a boundary condition on the state variable 
at the top. Incentive compatibility requires that ( 7$)$, which is the state equation in our problem, holds. Moreover, it is well known from the literature on regulation ${ }^{8}$ that, when the cost function is linear in output, the condition that the price schedule is nondecreasing in $c$ is sufficient for incentive compatibility. Finally, we have to add the two constraints that the maximum expected penalty is not greater than the maximum penalty allowed and that the minimum expected penalty is non negative. The first constraint is already encompassed by the participation constraint (12), while the requirement of non negative penalties will bind for the most efficient cartel, being the expected penalty increasing in the observed price.

The problem for the enforcer is therefore

$$
\begin{aligned}
\max _{p_{c}} E W(p)= & \int_{\underline{c}}^{\bar{c}}\left[C S\left(p_{c}\right)+e s\left(p_{c}\right)+\Pi_{c}\left(p_{c}\right)-(k / \bar{s}) e s\left(p_{c}\right)\right] g(c) d c \\
\text { s.t. } & \\
& \frac{d \Pi_{c}}{d c}=-D\left(p_{c}\right) \\
& \prod_{\bar{c}}\left(p_{\bar{c}}\right) \geq \max \left\{0, u_{\bar{c}}\left(p_{\bar{c}}\right)-\bar{s}\right\} \\
& u_{\underline{c}}\left(p_{\underline{c}}\right)-\Pi_{\bar{c}}\left(p_{\bar{c}}\right)-\int_{\underline{c}}^{\bar{c}} D\left(p_{c}\right) d c \geq 0 \\
& p_{c} \in\left[c, p_{c}^{m}\right]
\end{aligned}
$$

and $p_{c}$ being nondecreasing. Notice that we have set the penalty at the maximum level in order to minimize the costs of enforcement. We will proceed as usual by solving a relaxed problem in which the condition that the price schedule is nondecreasing is ignored, checking once solved that this requirement is met. Substituting (10) for $e s\left(p_{c}\right)$ and integrating by parts we obtain:

$$
\begin{aligned}
E W(p)= & \int_{\underline{c}}^{\bar{c}}\left[C S\left(p_{c}\right)+u_{c}\left(p_{c}\right)-(G(c) / g(c)) D\left(p_{c}\right)+\Pi_{c}\left(p_{c}\right)\right. \\
& \left.-\Pi_{\bar{c}}\left(p_{\bar{c}}\right)-(k / \bar{s}) e s\left(p_{c}\right)\right] g(c) d c
\end{aligned}
$$

Being $\Pi_{\bar{c}}\left(p_{\bar{c}}\right)$ welfare decreasing, the participation constraint will bind at the top. The Hamiltonian of our problem is therefore:

\footnotetext{
${ }^{8}$ See for instance, Baron (1989), p. 1369 for a proof.
} 


$$
\begin{aligned}
H= & \left\{C S\left(p_{c}\right)+(1-k / \bar{s})\left[u_{c}\left(p_{c}\right)-D\left(p_{c}\right) G(c) / g(c)-\max \left(0, u_{\bar{c}}\left(p_{c}^{m}\right)-\bar{s}\right)\right]\right. \\
& \left.+\Pi_{c}\left(p_{c}\right)\right\} g(c)-\lambda(c) D\left(p_{c}\right)+\mu\left(u_{\underline{c}}\left(p_{c}\right)-\int_{\underline{c}}^{\bar{c}} D\left(p_{c}\right) d c\right. \\
& \left.-\max \left(0, u_{\bar{c}}\left(p_{c}^{m}\right)-\bar{s}\right)\right)+\gamma(c)\left(p_{c}^{m}-p_{c}\right)
\end{aligned}
$$

We initially consider the optimal enforcement when prosecution is costless, i.e. $k=0$, or alternatively, when the cost of enforcement is fixed. This preliminary result will make it clear that the cost of enforcement is only a part of the problem, and that even when prosecution can be increased costlessly within the participation constraint, asymmetric information plays a major role in the solution.

Proposition 4 Suppose the prosecution costs $k$ be zero and the maximum penalty be very high $\left(\bar{s} \geq u_{\bar{c}}\left(p_{\bar{c}}\right)\right.$. The optimal price schedule implementable is

$$
p_{c}=\min \left\{c+\frac{g(\underline{c})}{g(c)} \frac{\int_{\underline{c}}^{\bar{c}} D\left(p_{c}\right) d c}{D\left(p_{\underline{c}}\right)}, p_{c}^{m}\right\}
$$

Proof: Notice that the Hamiltonian is concave in $p_{c}$ as well as the constraint of non negative penalties. Hence, the solution of our optimal control problem solves the following equations:

$$
\begin{gathered}
\frac{\partial H}{\partial p_{c}}=\left\{\left(p_{c}-c-(G(c) / g(c)) D^{\prime}\left(p_{c}\right)+d \Pi_{c} / d p_{c}\right\}-(\lambda(c)+\mu) D^{\prime}\left(p_{c}\right)-\gamma(c)=0\right. \\
\frac{d \lambda}{d c}=-\frac{\partial H}{\partial \Pi_{c}}=-g(c) \quad \lambda(\underline{c})=0 \\
\frac{\partial H}{\partial \mu}=u_{\underline{c}}\left(p_{\underline{c}}\right)-\int_{\underline{c}}^{\bar{c}} D\left(p_{c}\right) d c=0 \\
\frac{\partial H}{\partial \gamma(c)}=p_{c}^{m} \geq p_{c}
\end{gathered}
$$

Integrating ( 15 ) we obtain $\lambda(c)=-F(c)$. Substituting in (14) and taking into account that $d \Pi_{c} / d p_{c}=0$ for incentive compatibility, we obtain after rearranging 


$$
p_{c}=c+\frac{\mu}{g(c)}+\frac{\gamma(c)}{g(c) D^{\prime}}
$$

Substituting in $(16)$ and guessing that $p_{\underline{c}}<p_{\underline{c}}^{m}$, i.e. $\gamma(\underline{c})=0$, we obtain:

$$
\frac{\mu D\left(p_{\underline{c}}\right)}{g(\underline{c})}=\int_{\underline{c}}^{\bar{c}} D\left(p_{c}\right) d c
$$

Substituting in (14) and solving we obtain the expression of the price schedule, with $\gamma(c)$ adjusting for the price to be not greater than the monopoly price; notice that the price schedule is nondecreasing in $c$, as required by incentive compatibility. Moreover, substituting the equilibrium price in the participation constraint for the highest cost type and in the non negative penalties constraint for the lowest cost type, it is easy to check that both are strictly binding. Finally, (14) for the lowest type would contain also the term $\mu d u_{\underline{c}} / d p_{\underline{c}}>0$, which would imply a different expression and a higher level of the welfare maximizing price, breaking the monotonicity constraint at the bottom. However, we are free to assign any value to the control at the points of discontinuity ${ }^{9}$ without affecting the value of the Hamiltonian, being the distribution of $c$ non atomic. Hence, we simply apply the expression above of the optimal price also to the lowest type.

The result obtained requires some comments. We have seen that incentive compatibility requires to create rents for the more efficient types. If positive transfers are not allowed, as is the case when we can use only fines, informational rents must be created through price cost margins. Notice that the price schedule adds to the marginal cost $c$ the mark-up $\mu / g(c)$ : if the density distribution $g(c)$ is not increasing too much, it means that the allocative distortion is larger for less efficient types. For instance, with a uniform distribution of types, the additive mark-up is the same for all cartels, and therefore the price schedule is less distortionary for more efficient cartels. This is the outcome of two conflicting forces at work: on the one hand the traditional "no distortion at the top (at the bottom, in our case)" principle; on the other hand the need to create sufficient incentives (rents) for efficient types to induce them to price below their monopoly price. When positive transfers are not allowed, it is not possible to separate the incentive and the

\footnotetext{
${ }^{9}$ See for instance Seiertad and Sydsaeter (1987), p.73.
} 
allocative problem, reaching the first best. In our constrained problem of antitrust enforcement we cannot separate the two tasks, and therefore we are able to implement only a second best outcome.

Moreover, it must be noticed that transfering fines to consumers plays an important role in the welfare maximization problem: we allow less efficient firms to set prices closer to their monopoly level, but we fine them increasingly transferring the penalty to the consumers with no additional distortion. In some cases it is too optimistic to assume that this transfer can be implemented without distortion: for instance, we might not be able to identify the consumers which are active in the market involved, or there might be additional costs for the firm, as lost reputation, with no associated transfer to the consumers. But the simpler case in which fines are not pure transfers is when the enforcement is costly.

Hence, we now consider the optimal enforcement policy with costly prosecution, maintaining the assumption of maximum penalties sufficiently high.

Proposition 5 The optimal enforcement policy with costly prosecution and $\bar{s} \geq u_{\bar{c}}\left(p_{\bar{c}}\right)$ implements the price schedule identified by the following expression ${ }^{10}$ :

$$
-D\left(p_{c}\right)+\frac{\partial u_{c}}{\partial p}-(\mu / g(c)) D^{\prime}\left(p_{c}\right)-\frac{k}{\bar{s}}\left[\frac{\partial u_{c}}{\partial p}-\frac{G(c)}{g(c)} D^{\prime}\left(p_{c}\right)\right]-\gamma(c)=0
$$

The result above can be easily proved on the same line of argument of the previous proposition. Consider the different terms of the expression. The first two terms correspond to the gross welfare variation when the price is increased, i.e. the variation in consumer surplus and gross profits. In the first best allocation they would balance out.

The other terms take into account the enforcement problem and constraints: $-D^{\prime} \mu / g(c)$ is positive and determines the creation of price cost margins and increasing allocative distortions for less efficient types, as we have seen in the case of costless enforcement. The last term in brackets is related to enforcement costs, which add to the other terms in balancing marginal benefits and costs in terms of welfare ${ }^{11}$. Since this negative term

\footnotetext{
${ }^{10}$ We assume $k / \bar{s}$ to be sufficiently small to ensure that the second order conditions hold.

${ }^{11}$ This term can be rewritten as $\left(\partial u_{c} / \partial p\right) g(c)-G(c) D^{\prime}$. If the enforcer allows type $\hat{c}$ to set a higher price, he has to raise the prosecution rate applied to type $\hat{c}$ by $d u_{\hat{c}} / d p$ in order to deter higher types from switching to that higher price. Since the frequency of type $\hat{c}$ is $g(\hat{c})$, this explains the first term. On the other hand, if $p_{\hat{c}}$ is higher, it becomes realively
} 
in absolute terms becomes larger, through $G(c)$, as $c$ increases, the incentive to increase price over costs is reduced for less efficient types, balancing the previous effect of an (almost) fixed additive mark up $\mu$. This conclusion is in line with our intuition: if penalties are distortionary, allowing high prices for inefficient types and using fines to transfer welfare to consumers is inefficient, and we prefer to limit the increase in price cost margins for less efficient types.

\section{Antitrust vs regulation}

We pointed out that often the design of supply side policy intervention has to choose between competition policy and regulation. The framework we have developed to analyse antitrust enforcement allows quite naturally to compare the outcomes implementable through competition policy with those obtainable through regulation. This latter encompasses obviously a very broad set of policies, which differ in terms of instruments and market structure; hence we do not pretend to perform a complete analysis of the issue. However, it seems interesting to compare, in terms of welfare, optimal antitrust enforcement with two regulatory regimes: when the regulator can use transfers to firms and when transfers are banned.

More precisely, consider the following policy regimes, all characterized by asymmetric information of the public authority on the costs of the firm(s).

AE (Antitrust enforcement): optimal prudential enforcement through fines, with no cost of prosecution $(k=0)$ and sufficiently high maximum penalty $\left(\bar{s} \geq u_{\bar{c}}\left(p_{\bar{c}}\right)\right)$

RT (Regulation with transfers): regulation through a menu of contracts which specify a price $p(\hat{c})$ and a transfer $T(\hat{c})$ as a function of the reported costs $\hat{c}$.

RNT (Regulation with no transfer): regulation through a menu of contracts which specify a price $p(\hat{c})$ as a function of the reported costs $\hat{c}$.

AE corresponds to the optimal enforcement policy with costless prosecution analysed above. RT is referred to the Baron and Myerson (1982)

more attractive for cartel types $c<\hat{c}$, and the enforcer must increase expected penalties by $D^{\prime}\left(p_{\dot{c}}\right)$ on $c<\hat{c}$ without affecting marginal deterrence. Since $G(\hat{c})$ is the mass of those types, the second term is explained. 
model of regulation of a monopolist with unknown costs and RNT is the case in which the regulator cannot use transfers to the regulated firm. The following proposition establishes the ranking in terms of welfare among the three regimes.

\section{Proposition $6 E W_{R T}>E W_{A E}>E W_{R N T}$}

Proof: We'll show that the three regimes can be expressed as different versions of the same mechanism design problem we analysed in the previous sections. The key point is the equivalence between direct mechanisms, those usually considered in the regulatory problem, and indirect mechanisms we used in the enforcement problem. Moreover, the assumption of perfectly correlated costs within the cartel makes the monopoly and oligopoly industrial structures perfectly comparable.

Compare first AE and RT. If we do not impose the constraint of non negative penalties in the enforcement problem analysed in proposition 4, i.e. if we set $\mu=0$, we obtain $p_{c}=c$, i.e. the first best allocation for all types. Substituting in the expected penalty equation we have:

$$
e s\left(p_{c}\right)=-\int_{c}^{\bar{c}} D\left(p_{c}\right) d c
$$

implying a positive transfer for all cartel types except the highest $\bar{c}$, which breaks even. This result corresponds to the solution of the Baron and Myerson (1982) model of regulation of a monopolist with unknown costs. Since the AE regime corresponds to the RT problem with an additional constraint of non negative penalties (negative transfers) the expected welfare will be lower in this regime.

Compare now AE and RNT. In this latter case the regulator has no way to create rents through transfers, and therefore we expect allocative distorsions. Moreover, the participation constraint implies that no price below $\bar{c}$ can be imposed, since costs are unknown. Hence, the menu of contracts as a function of the reported cost $\hat{c}$ is $p(\hat{c})=p_{\hat{c}}^{m}$ for $\hat{c} \in[\underline{c}, \tilde{c}]$ and $p(\hat{c})=\bar{c}$ for $\hat{c} \in(\tilde{c}, \bar{c}]$, where $\tilde{c}$ is such that $p_{\tilde{c}}^{m}=\bar{c}$. This mechanism clearly induces truthtelling revelation and solves incentive compatibility. The participation constraint will bind for the less efficient type. This mechanism is equivalent, in terms of outcomes, to the following expected penalty schedule for an $\mathrm{AE}$ problem: $e s\left(p_{c}\right)=0$ for $p_{c} \leq \bar{c}$ and $e s\left(p_{c}\right)=\bar{s}$ for $p_{c}>\bar{c}$. This penalty schedule, given that $\bar{s} \geq u_{\bar{c}}\left(p_{\bar{c}}\right)$ will induce bunching at $\bar{c}$ for all the cartels less efficient that $\tilde{c}$. Since the RNT problem can be entirely formulated as an AE 
problem with no further constraint, and its allocation does not correspond to the AE outcome, RNT must be inferior with respect to AE.

Proposition 6 shows that competition policy is inferior with respect to regulation when this latter can use transfers: in this case, in fact the regulator is able to completely separate the incentive and the allocative problem reaching the first best. However the antitrust approach seems preferable when regulation cannot use transfers, as in a price cap regime: negative transfers - penalties - allow in fact to use more powerful mechanisms and to implement more efficient outcomes. Figure 1 shows the allocations implemented in the three regimes.

Figure 1 about here

The RT regime (- - line) implements the first best through transfers (negative penalties); the $\mathrm{AE}$ regime leaves rents through price cost margins at a lower level for efficient types than the RNT regime, in which cartels up to the $\tilde{c}$ type choose their monopoly price.

\section{Concluding remarks}

In this paper we have analyzed the optimal prudential enforcement of antitrust law under asymmetric information on cartel's costs. The main features of the optimal policy are:

- The policy implements second best allocations with price cost margins for all the cartel types; hence, prices higher than marginal cost are not necessarely prosecuted even if they are indirectly evidence of (partial) collusion.

- The price cost margins tend to be lower for more efficient types;

- The expected penalty is increasing in observed price;

- Efficient cartels obtain (informational) rents while the least efficient cartel (eventually) breaks even;

- The antitrust enforcement regime is inferior with respect to a regulatory regime when transfers to firms are allowed, but is preferable to the situation in which regulators cannot use transfers, as in the price cap case. 
The key ingredient of our result is the interplay between asymmetric information and "prudential" enforcement, i.e. the constraint not to induce losses even off the equilibrium path: if cartel types were observable either ex ante or ex post and sufficiently severe penalties might be used as a deterrent, first best allocations would be implementable provided that very high fines were feasible. Under asymmetric information partecipation and incentive compatibility constraints severely limit the set of implementable price schedules, and positive rents must be created for more efficient types in order to prevent them from setting higher prices.

These results differ from those in Besanko and Spulberg (1989) for the two types case and from Penard and Souam (1996) for a continuoum of types, which all admit severe penalties off the equilibrium path. In those papers the efficient type(s) collude while the inefficient(s) behave noncooperatively.

In this paper we have focussed our analysis on a particular feature that positively identifies antitrust policy and distinguishes it from regulation, i.e. the feasibility of negative transfers to firms. When we compare competition policy with regulation there are other features which seem relevant, and that might be considered in future research.

First of all, regulation tends to define the menu of contracts ex ante, while typically antitrust is in most cases an ex post intervention: we bypassed this problem by assuming that the enforcer is able to commit to a policy, for instance by issuing guidelines and by building a reputation over time ${ }^{12}$. The problem of commitment, however, is not specific to antitrust, and becomes extremely serious in regulation as well, once this latter is considered in a dynamic setting.

Secondly, competition policy is used in oligopoly situations while regulation is mainly conceived for monopoly: in our setting we do not exploit this structural difference and the enforcer treats the cartel as a single entity. An interesting case would be to design prosecution against collusion in order to induce some of the participants to reveal evidence on illegal behaviour, reducing the cost of enforcement.

Thirdly, in a broader political economy perspective, the regulatory capture issue seems quite different in the two insitutional settings we are comparing: regulation is strictly tied to the firm regulated in a long run and stable relationship; on the contrary an antitrust authority is competent over

\footnotetext{
${ }^{12}$ The no commitment case in antitrust enforcement is for instance considered for the two types case in Martini and Rovesti (1997).
} 
a wide range of industries and no sistematic relationship tends to occur. Hence, firms' pressure and lobbying in the initial phase when the policy is designed is much less likely in competition policy. However, if competition policy maintains a certain degree of ex post discretion with respect to regulation, the incentives to bribe ex post might be higher.

\section{References}

[1] Amstrong M., Cowan S. Vickers J. (1994), Regulatory Reform: Economic Analysis and British Experience, Cambridge, MIT Press.

[2] Baron D. (1989), Design of Regulatory Mechanisms and Institutions, in R.Schmalensee, R. Willig (eds.), Handbook of Industrial Organization, North Holland, vol. 2, pp.1347-1444

[3] Baron D., Myerson R. (1982), Regulating a Monopolist with Unknown Costs, Econometrica, 50:911-30.

[4] Becker G. (1968), Crime and Punishment: an Economic Approach, Journal of Political Economy, 76:169-217.

[5] Besanko, D. Spulber D. (1989), Antitrust Enforcement under Asymmetric Information, The Economic Journal, 99:408-25.

[6] Martini G. Rovesti C. (1997), Welfare Effects of Antitrust Policy under Different Regimes: is Commitment Better than Discretion? mimeo.

[7] Mokherjee D., Png I. (1994), Marginal Deterrence in Enforcement of Law, Journal of Political Economy, 102:1039-1066.

[8] Penard T., Souam S. (1996), Optimal Antitrust Policy Under Asymmetric Information and Budget Constraints, mimeo, University of Paris I, Pantheon-Sorbonne.

[9] Seierstad A., Sydsaeter K. (1987), Optimal Control Theory with Economic Applications, North Holland 